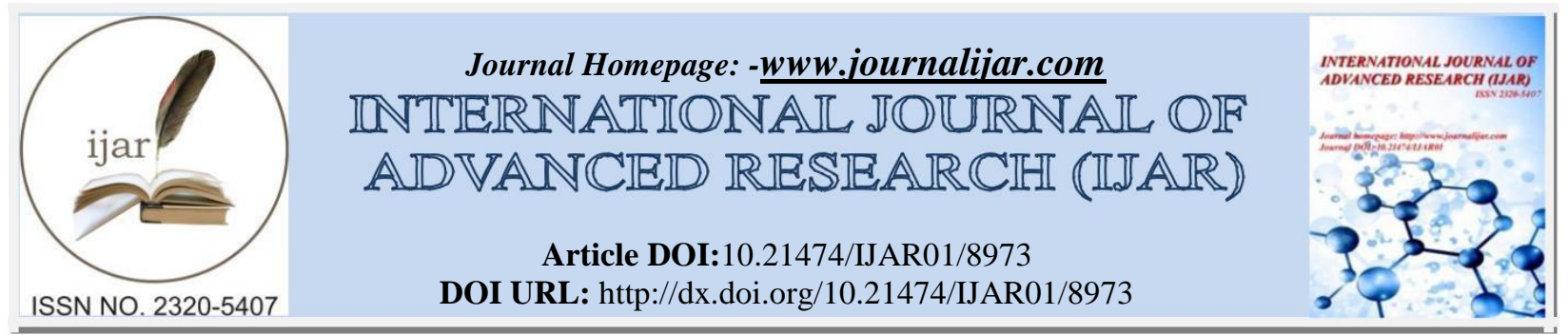

RESEARCH ARTICLE

\title{
A STUDY TO ASSESS THE PREVALENCE OF WHATSAPP ADDICTION AMONG NURSING STUDENTS OF HIMALAYAN SCHOOL OF NURSING KALA-AMB DISTRICT SIRMAUR, HIMACHAL PRADESH.
}

\section{Kiran Bala, Kusum Devi, Mamta Rani, Manisha Devi, Manju Bala, Manpreet Kaur, Pingla Devi , Prachika Kashyap and Priyanka.}

GNM 3rd year students of Himalayan School of Nursing Kala -Amb district Sirmour Himachal Pardesh Guided by Ms RENU BALA Lecturer Community Health Nursing.

\section{Manuscript Info}

…………………

\section{Manuscript History}

Received: 24 February 2019

Final Accepted: 26 March 2019

Published: April 2019

Key words:-

Nursing students, Prevalence,

Whatsapp Addiction.
Abstract

Objective:To assess the prevalence of whatsapp addiction among nursing students of Himalayan school of nursing Kala-Amb Himachal Pradesh.

Methodology:A cross sectional descriptive study was used, a sample size of 60 nursing students were selected by using Purposive sampling technique, Semi structured questionnaire were used to assess the prevalence of whatsapp addiction among nursing students of Himalayan school of nursing Kala-Amb Himachal Pradesh.

Result: The study revealed that among 60 Nursing students, Benefits of using whatspp is easy way $57(95 \%)$, improve IPR $40(66.6 \%)$, building friendship 42(70\%), fast and speedily 50(83.3\%), and long distance communication 56(93.3\%). The Drawback of using whatspp is unwanted relations 32(53.3\%), lack interaction without society $37(61.6 \%)$, no face to face interaction $48(80 \%)$ ignoring people around use $30(50 \%)$, and reduce attachment with parents $32(53.3 \%)$. When not using how you do feel are happy 39 (65\%), calm 35(58.3), loneliness $27(45 \%)$, restlessness $23(38.3 \%$ ) and stress $15(25 \%)$. Whatspp is mainly used for the group 51(85\%),friends 60(100\%), relatives 59(98.3\%),(Education purpose 53(88.3\%) and General purpose $46(76.6 \%)$.

Copy Right, IJAR, 2019,. All rights reserved.

\section{Introduction:-}

The world is dynamically changing due to the advancement in the mobile technology. These days it is almost impossible to avoid the presence of mobile applications or called Mobile Apps.

Most of the people can praise the various mobile applications that they use in their everyday lives. Several people are heavily dependent of the usage of such applications for their day to day activities.

Whatsapp is one among the major change in mobile app communication in the recent past, it users is growing very fast on mobile phones and also on the computers. 
Whatsaap was created by Jan koum and action in 2009 for easy communication and faster multimedia messaging. Communication through mobile phones has become easier, faster and chapter with the help of whatsaap messenger. It is cheaper when compared to the normal phone messaging. Whatsaap messenger is a cross platform mobile messenger which is being worked through internet data plan. Whatsaap provides users to send and receive Medias like, video, and images.

Whatsaap addiction is syndrome is a part of internet addiction disorder. Internet addiction disorder may be broadly defined as "the inability of individuals to control their internet use, resulting in marked distress and / or functional impairment in daily life." One of the studies conducted in South Korea on internet addition disorder influence suicide related behavior.

The application is highly addictive and creates a great impact on regular users, and apart form that it becomes difficult to control and cure. They can do the positive and negative with whatsaap. This study focus on the prevalence of whatsaap addiction among nursing students.

\section{Materials Method:-}

This is a cross sectional descriptive study which was done among the GNM $1^{\text {st }}$ and GNM $2{ }^{\text {nd }}$ student of Himalayan school of nursing Kala-Amb. Verbal consent and ethical committee clearance was obtained from the student before handing over the questionnaire. They were requested to fill the Performa with full assurance about the confidentially and anonymity that data would be used only for scientific purpose the questionnaire was then administered to 60 students. To assess the prevalence of whatsapp addiction among nursing students of Himalayan school of nursing Kala-Amb Himachal Pradesh. Nursing Students not available during the study and not willing to participate were excluded from the study. The data is analyzed by using suitable statistical methods.

Results:-

Table 1:- frequency and percentage distribution of socio-demographic characteristics of nursing students.

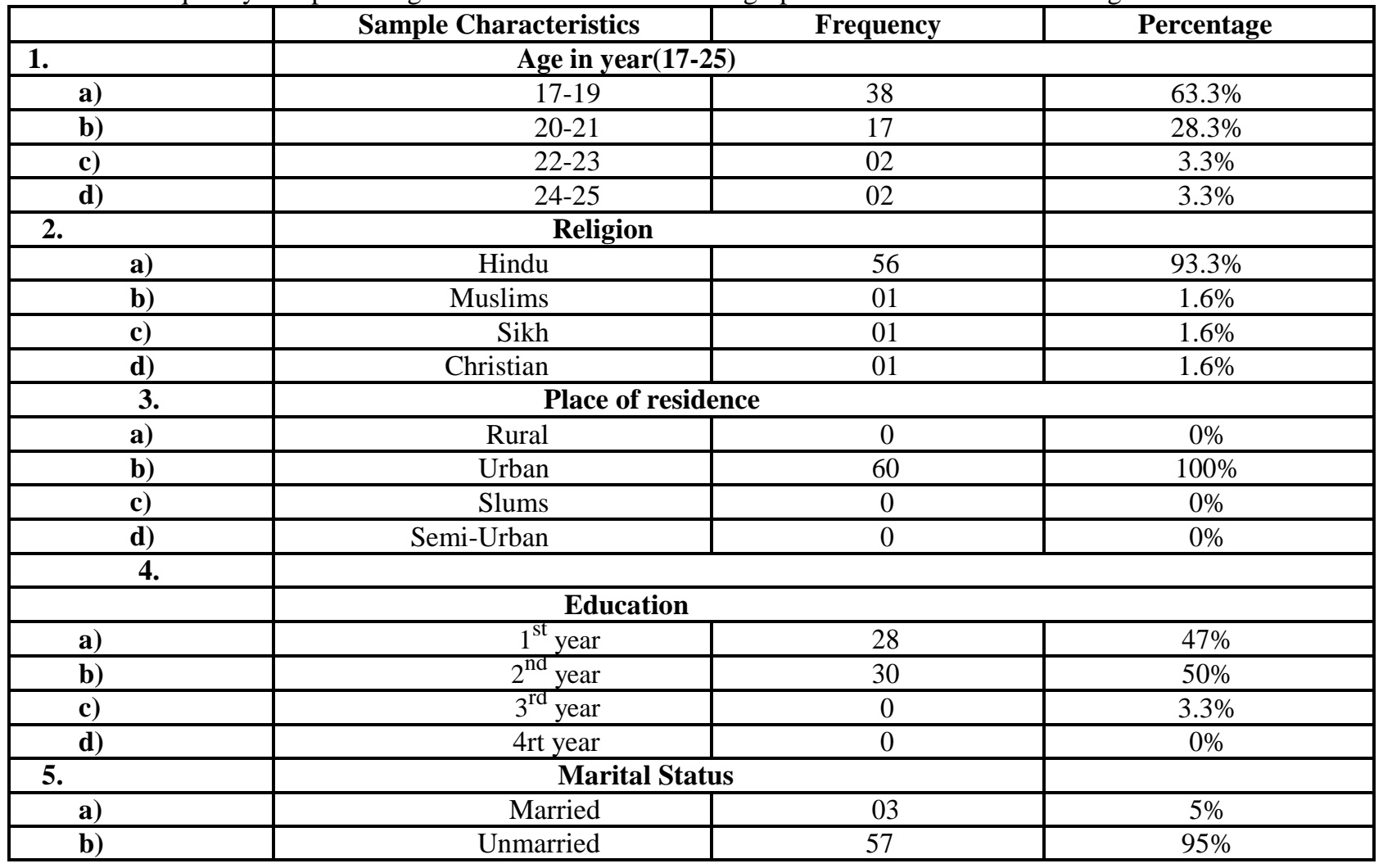

Table 1:- In relation to age greater number of nursing students $66.3 \%$ where in the age group (17-19 years) and lesser number $3.3 \%$ in the age group of (24-25 years). Most of nursing students $93.3 \%$ was Hindu, or lesser number $1.6 \%$ 
Muslims, Sikh, and Christian. Majority of nursing student was unmarried 95\% and least 5\% were married. According to place of residence all nursing student from urban area 100\%. 60 nursing students were taken by simple randomization sampling from each GNM stream, GNM $1^{\text {st }}$ year, $2^{\text {nd }}$ year.

Table 2:- frequency and percentage distribution of Semi-structured questionnaire were used to assess the prevalence of whatsapp addiction among nursing students.

\begin{tabular}{|c|c|c|c|}
\hline S.NO. & Items & Frequency & Percentage \\
\hline 1. & \multicolumn{3}{|c|}{ Benefits of using whatsapp? } \\
\hline a) & Easy way & 57 & $95 \%$ \\
\hline b) & Improve IPR & 40 & $66.6 \%$ \\
\hline c) & Building friendship & 42 & $70 \%$ \\
\hline d) & Fast and speedily & 50 & $83.3 \%$ \\
\hline e) & Long distance communication & 56 & $93.3 \%$ \\
\hline 2. & \multicolumn{3}{|c|}{ Drawback of using whatsapp? } \\
\hline a) & Unwanted relations & 32 & $53.3 \%$ \\
\hline b) & Lack interaction without society & 37 & $61.6 \%$ \\
\hline c) & No face to face interaction & 48 & $80 \%$ \\
\hline d) & Ignoring people around use & 30 & $50 \%$ \\
\hline e) & Reduce attachment with parents & 32 & $53.3 \%$ \\
\hline 3. & \multicolumn{3}{|c|}{ When not using whatsapp how do you feel? } \\
\hline a) & Happy & 39 & $65 \%$ \\
\hline b) & Calm & 35 & $58.3 \%$ \\
\hline c) & Loneliness & 27 & $45 \%$ \\
\hline d) & Restlessness & 23 & $38.3 \%$ \\
\hline e) & Stress & 15 & $25 \%$ \\
\hline 4. & \multicolumn{3}{|c|}{ Whatsapp is mainly use for? } \\
\hline a) & Group & 51 & $85 \%$ \\
\hline b) & Friends & 60 & $100 \%$ \\
\hline c) & Relatives & 59 & $98.3 \%$ \\
\hline d) & Education purpose & 53 & $88.3 \%$ \\
\hline e) & General purpose & 46 & $76.6 \%$ \\
\hline
\end{tabular}

Table 2:- Benefits of using whatspp is easy way 57(95\%), improve IPR 40(66.6\%), building friendship 42(70\%), fast and speedily 50(83.3\%), and long distance communication 56(93.3\%). The Drawback of using whatspp is unwanted relations $32(53.3 \%)$, lack interaction without society $37(61.6 \%)$, no face to face interaction $48(80 \%)$ ignoring people around use 30(50\%), and reduce attachment with parents 32(53.3\%). When not using how you do feel are happy $39(65 \%)$, calm 35(58.3), loneliness $27(45 \%)$, restlessness $23(38.3 \%)$ and stress $15(25 \%)$.Whatspp is mainly used for the group 51(85\%), friends 60(100\%), relatives 59(98.3\%),(Education purpose 53(88.3\%) and General purpose $46(76.6 \%)$. 


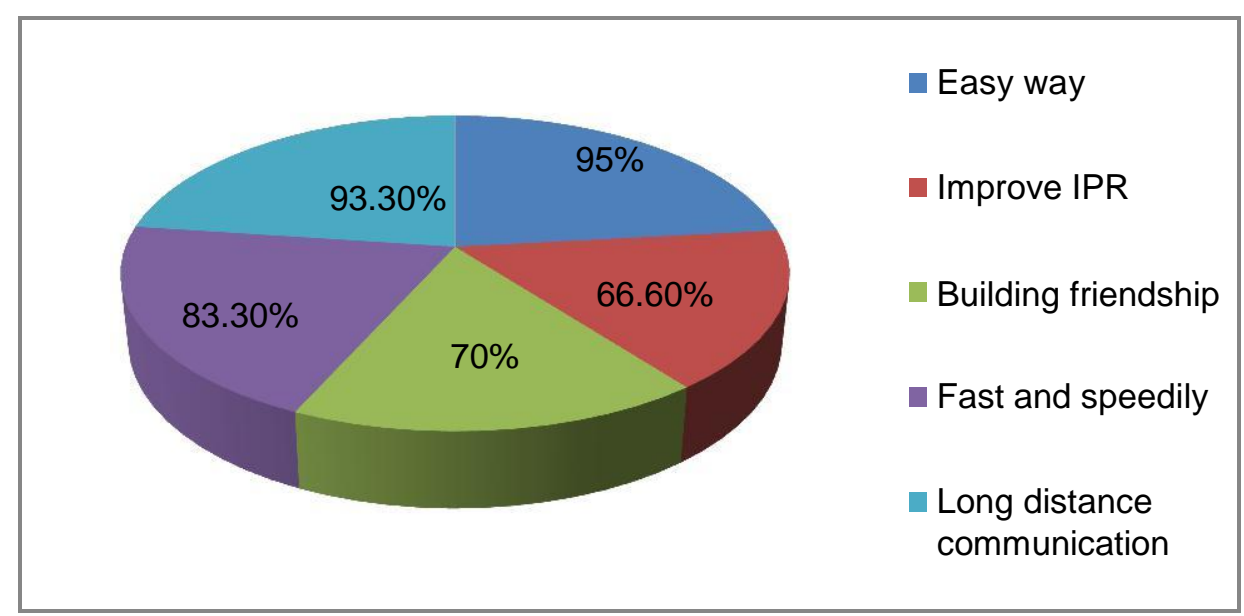

Figure no 1:-Benefits of using whatsapp?

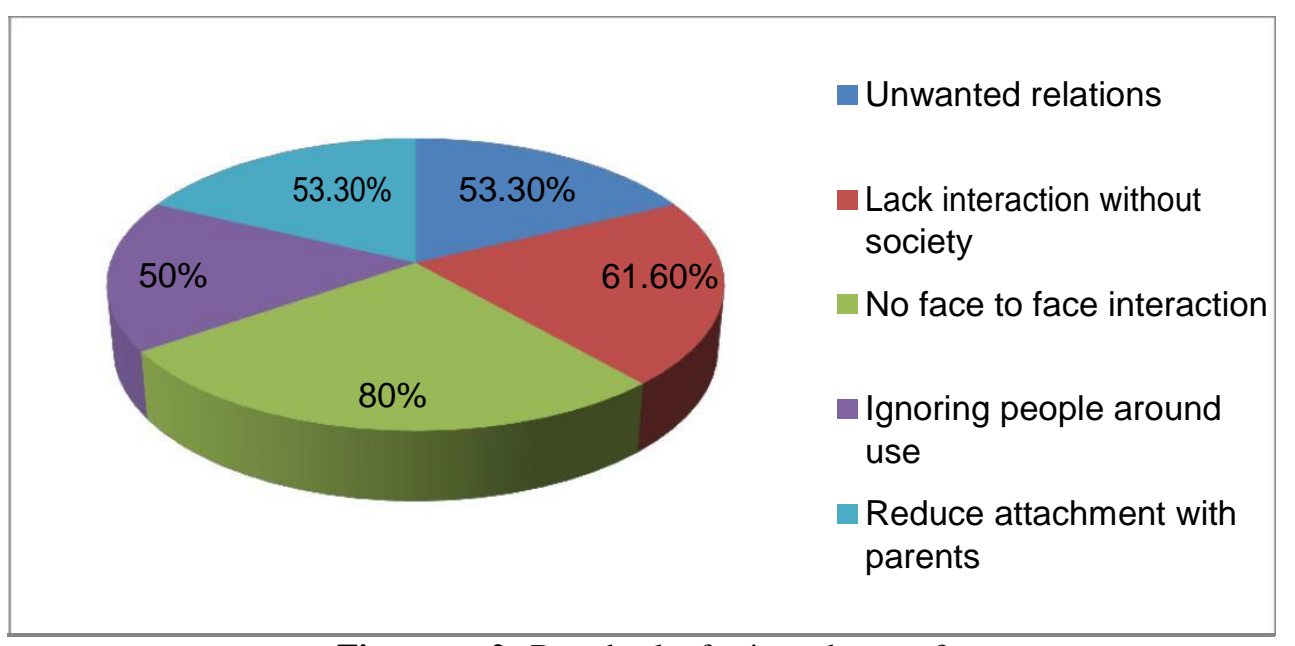

Figure no 2:-Drawback of using whatsapp?

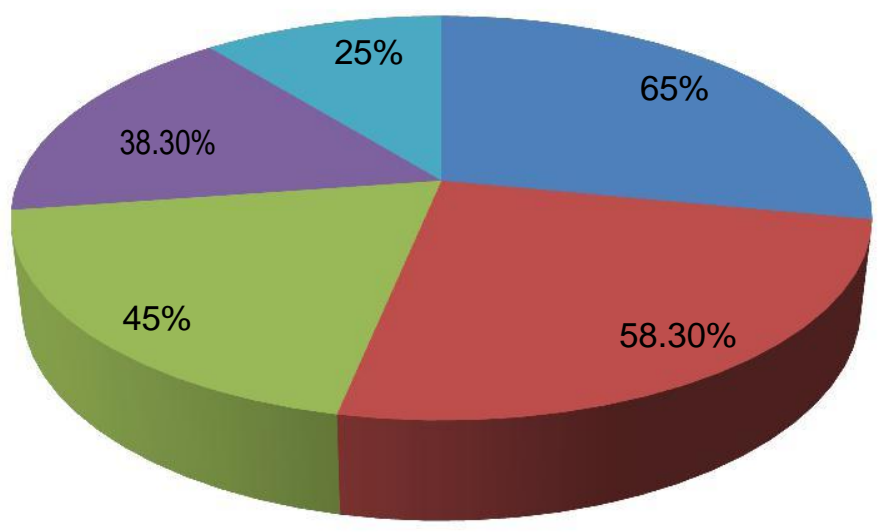

- Happy

- Calm

- Loneliness

- Restlessness

- Stress

Figure no 3:-When not using whatsapp how do you feel? 


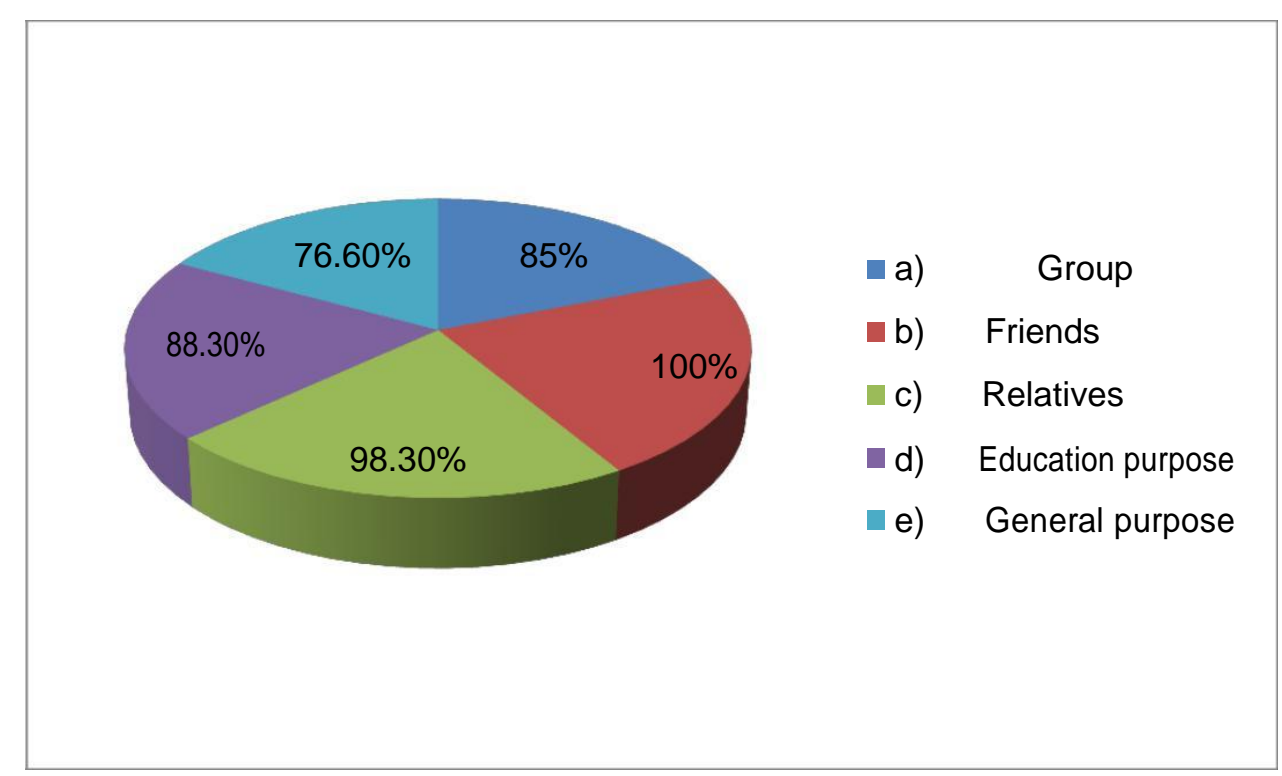

Figure no 4:-Whatsapp is mainly use for?

\section{Conclusion:-}

The prevalence of whatsapp addiction is high, were in more than half study group show some form of whatsapp addiction pattern. The whatsapp addiction problem among Nursing Students should gain attention and it is time to evolve a comprehensive intervention approach to promote a healthy and safe whatsapp use

\section{Conflict Of Interest:-}

There was no such conflict and bias during the study.

\section{Source Of Finding: -}

it is self-funded research study.

\section{Ethical Clearance:-no}

ethical issue exists.

\section{Reference:-}

1. Jang YJ,Kim CW,the evolution of smart phone market and the effect by android, journal of KIISE, 2010,28(5):48-56,

2. V.P. karthileyan1, tony Varghese olassayil2 and sanal jacob3 "a study on impact of whatspp among nursing student in Coimbatore district , Indian stream research journal volume4 issue 12 jan 2015.

3. WHO management of substance abuse: dependence syndrome. [Last updated an 2015 march 26; last cited on 2014 mar 262] whatspp -Wikipedia, the free encyclopedia https; Ilen.m.wikipedia.org|wikilwhatspp.

4. 4)Yuan $\mathrm{K}$, qin $\mathrm{W}$,Wang $\mathrm{G}$,zeng $\mathrm{F}$, Zhao $\mathrm{L}$,yangX,et al. micro structure abnormalities in adolescents with internet addiction disorder PLoS ONE.2011;6(6):e20708.

5. WWW.google.com

6. WWW.pubmed.com 